\title{
PROPERTIES AND FUNCTION OF PROTEINS IN EXCITABLE MEMBRANES: AN INTEGRAL MODEL OF NERVE EXCITABILITY *
}

\author{
David Nachmansohn \\ College of Physicians and Surgeons \\ Columbia University \\ New York, New York 10032 \\ and \\ Eberhard Neumann \\ Max-Planck Institut für biophysikalische Chemie \\ Göttingen, West Germany
}

As was stated by Hill ${ }^{1} 15$ years ago, the strong heat production and absorption that coincides with electrical activity leaves us with no alternative to the assumption that the changes of ion permeability in excitable membranes are associated with chemical reactions. These and other experimental facts are incompatible with the assumption that electrical activity is a simple electrodiffusion process, as is still maintained by some investigators. According to Cole, ${ }^{2}$ the Planck model does not apply to biological membranes.

A chemical theory of the events that take place in excitable membranes during electrical activity has been elaborated over the last three decades. The theory is based on the analyses of the properties and functions of the proteins and enzymes that process AcCh. ${ }^{3-i}$ Since 1937, the use of the electric organs of fish has been instrumental in these studies. Their extraordinarily high specialization in bioelectrogenesis offers a uniquely favorable material for the protein chemist.

As a result of the biochemical approach to the function of excitable membranes, it became apparent that $\mathrm{AcCh}$ is not a neurohumoral transmitter, as has been assumed, but is released and acts within the membrane. It is the signal that on excitation starts a series of reactions that lead to increased permeability (FIGURE 1). This series of reactions leads to the amplification of the signal. Many thousands of ions (about 20,000 to 30,000) cross the membrane in each direction per molecule of $\mathrm{AcCh}$ released. Two brief comments may be appropriate. The enzyme is uniformly distributed along the whole excitable membrane, in the conducting as well as in the junctional parts (FIGURE 2). The concentrations may differ in different types of excitable membranes; they are remarkably high in the excitable membrane of electroplax, in which about $10^{11}$ molecules of enzyme are present; the number of receptor molecules is of the same order of magnitude. The theory is not based upon the presence and the high concentrations of these proteins, however, but upon the many functional relationships between enzyme and receptor proteins and

* This work was supported, in part, by the National Science Foundation grant NSF-GB-31122, by the National Institutes of Health grant NS-03304, and by the New York Heart Association, Inc. 
electrical activity. Potent specific inhibitors of $R$ or $E$, for example, have been shown to affect electrical activity strongly in low concentrations in a great variety of preparations. In isolated fragments of the conducting parts of the electroplax membrane, which form microsacs, chemical stimulation of the acetylcholine receptor was shown by Kasai and Changeux ${ }^{*}$ to have similar effects on the ionic parameters (fluxes, permeabilities, and conductances) as

\section{AXON}

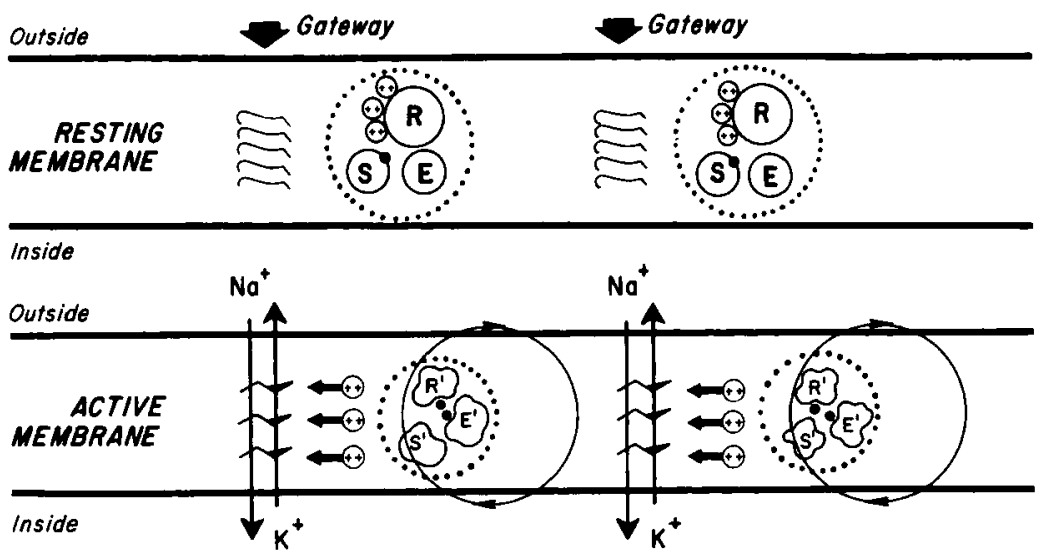

FIGURE 1. Schematic presentation of the role of $\mathrm{AcCh}$ in axonal parts of the excitable membrane. The upper part shows the membrane in resting condition. The three proteins that process AcCh form a tightly interlocked complex: the storage protein (S) to which AcCh (O) is bound in the resting condition, the $\mathrm{AcCh}$ receptor (R), and the enzyme AcCh esterase (E). This assembly is directly linked to an element referred to as a gateway, through which the ions presumably move during electrical activity. The $\mathrm{Ca}^{++}$ions are bound to $\mathrm{R}$. The lower part shows the active membrane. On excitation AcCh is activated, presumably by a conformational change of $\mathbf{S}$. It is translocated to $R$, inducing a conformational change $\mathrm{Ca}^{++}$ions are released probably by allosteric action), acting on the elements in the gateway, and inducing conformational changes of phospholipids, lipoproteins, or other components. These effects permit the accelerated ion movements. Many thousands of ions cross the membrane, about 20,000 to 30,000 in each direction per molecule of AcCh activated. AcCh thus acts as a signal, greatly amplified by a series of reactions. Simultaneously or subsequently, AcCh is translocated to E and hydrolyzed in a few millionths of a second. $R$ returns to its resting conformation and again binds $\mathrm{Ca}^{++}$. The barrier for ion movements is reestablished. But in the meantime, the electric fields that have been generated activate the adjacent unit.

electrical stimulation of axons (calculated in the same way by Hodgkin and Huxley ${ }^{15}$ and Dodge and Frankenhaeuser ${ }^{16}$ ), in which the proteins that process AcCh have been shown to be present and functional (TABLE 1).

Biomembranes, including the axonal ones, are nonequilibrium systems. The anisotropic distribution of ions on the two sides of the membrane is the result of the balance between active and passive transport. Thermodynamically active transport requires energy, which is provided by metabolic reactions. 


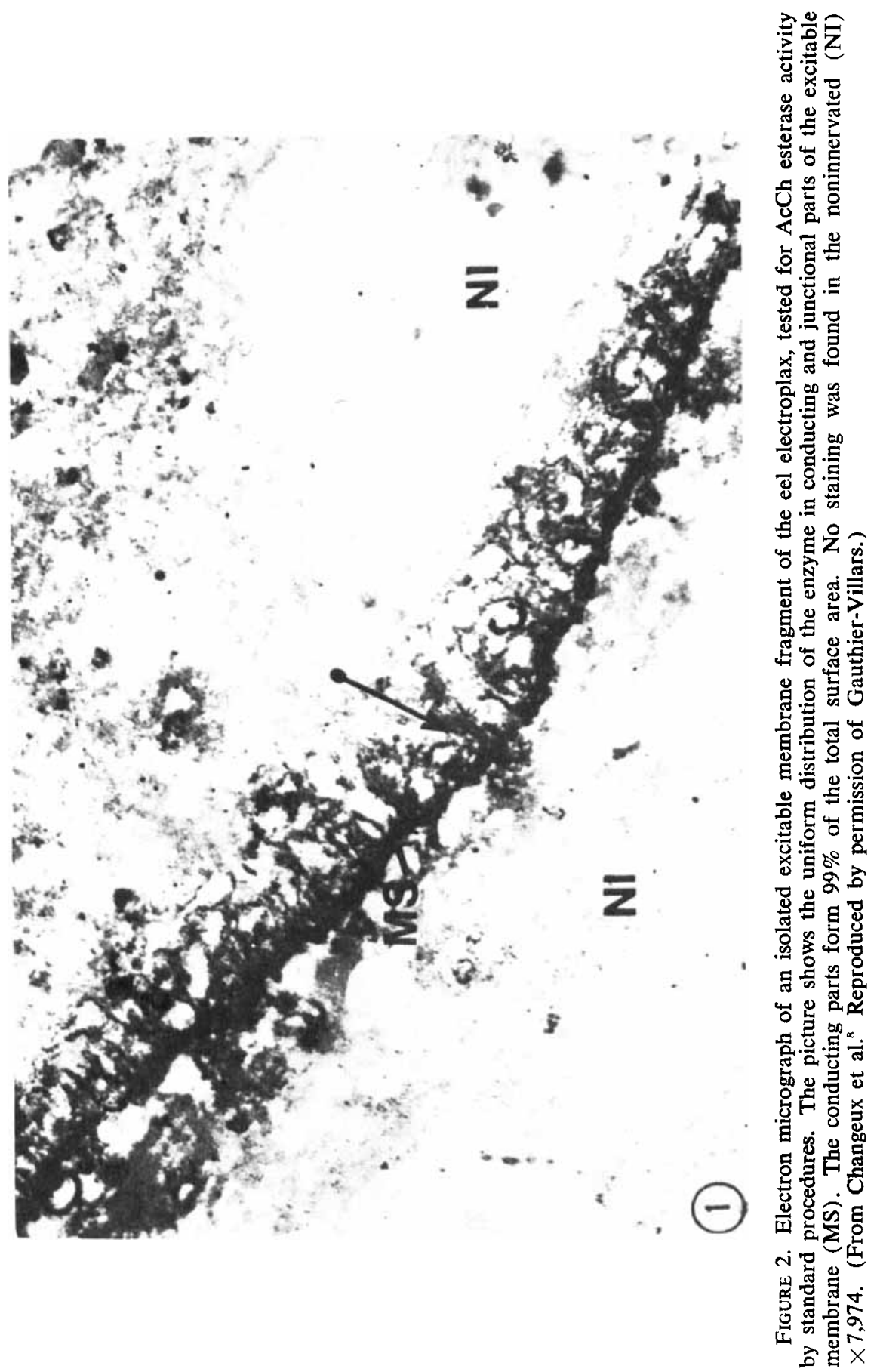


TABLE $1 *$

Parameters of ion Movements across Isolated Membrane Fragments of Electroplax, Stimulated by Activation of AcCh Receptor, and in Intact Axons, Stimulated Electrically $\dagger$

\begin{tabular}{|c|c|c|}
\hline Parameters & $\begin{array}{l}\text { Chemical } \\
\text { Stimulation } \\
\text { (microsacs) }\end{array}$ & $\begin{array}{c}\text { Electrical } \\
\text { Stimulation } \\
\text { (axons) }\end{array}$ \\
\hline $\begin{array}{l}\text { Fluxes } \\
\text { mol } / \mathrm{cm}^{2} / \mathrm{sec} \\
\Phi \mathrm{Na} \\
\Phi \mathrm{K}\end{array}$ & $\begin{array}{l}4 \times 10^{-13}(\text { efflux }) \\
2 \times 10^{-12}(\text { efflux })\end{array}$ & $\begin{array}{l}3.7 \times 10^{-12} \text { (influx) } \\
8.0 \times 10^{-11} \text { (efflux) }\end{array}$ \\
\hline $\begin{array}{l}\text { Permeabilities } \\
\text { cm/sec } \\
\text { p Na } \\
\text { p K }\end{array}$ & $\begin{array}{l}2 \times 10^{-0} \\
1 \times 10^{-8}\end{array}$ & $\begin{array}{l}3.3 \times 10^{-9} \\
7.4 \times 10^{7}\end{array}$ \\
\hline $\begin{array}{l}\text { Conductance } \\
\mathrm{mho} / \mathrm{cm}^{2} \\
\mathrm{~g} \mathrm{Na} \\
\mathrm{g} \mathrm{K}\end{array}$ & $\begin{array}{l}1 \times 10^{-6} \\
9 \times 10^{-6}\end{array}$ & $\begin{array}{l}3.3 \times 10^{-6} \\
2.4 \times 10^{-4}\end{array}$ \\
\hline
\end{tabular}

"From Kasai and Changeux."

†The isolated fragments of conducting parts of the excitable membrane form microsacs which may be filled with radioactive ions. The ion movements are obtained by activation of the receptor with $10^{-4} \mathrm{M}$ carbamylcholine. The data obtained through electrical stimulation are those reported for axons. ${ }^{15,10}$ The parameters were calculated by means of the same equations in both cases.

The chemodiffusion coupling can take place only in anisotropic systems, as was outlined repeatedly by Katchalsky. ${ }^{10}$ In view of the anisotropy, there is no direct relationship between the membrane potential $(\Delta \psi)$ and the logarithm of ion concentration; that is, the Nernst equation is not obeyed. Nonequilibrium thermodynamics provide a formal relationship for the steady state of zero ion flow $\left(I_{\mathrm{m}}=0\right)$ :

$$
(\Delta \psi)_{\mathrm{I} \mathrm{m}=0}=\Delta \psi_{\mathrm{D}}+\frac{R T}{F} \sum_{J} \frac{t_{J}}{z_{J}} \log _{\mathrm{n}} \frac{a_{J}^{(0)}}{a_{J}^{(1)}}
$$

where $\Delta \psi_{\mathrm{D}}$ are the Donnan contributions due to fixed surface charges, $R$ is the gas constant, $F$ the Faraday constant, $T$ the absolute temperature, $a_{j}$ is the thermodynamic activity (outside and inside the membrane, respectively) of the ion $J$ of the valency $z_{J}$, and the transference number $t_{J}$ represents the fraction of current carried by the $J$ ions in the membrane. $t_{J}$ and $\Delta \psi_{\mathrm{D}}$ depend on the membrane structure and therefore are not known. With $\Delta \psi_{\mathrm{D}}=0$ and $t_{J}=1$, Equation 1 simplifies to the Nernst equation for $J$ :

$$
(\Delta \psi)_{\operatorname{Im}=0}=\frac{R T}{z_{J} F} \log _{\mathrm{n}} \frac{a_{J}^{(0)}}{a_{J}^{(1)}}
$$

In view of our ignorance of the precise molecular structure of the membrane, a quantitative theory of the molecular events of bioelectricity is at 
present impossible. But it should be preceded by an integration of electrophysiological, biophysical, and chemical data into a picture that is at least qualitatively consistent. Such an integral approach was started several years ago, on the initiative of the late Aharon Katchalsky. It is a great privilege to present to you the integral model of nerve excitability as a memorial tribute to his brilliant mind. The model has recently been worked out in collaboration with Dr. Eberhard Neumann, and with the help of Professor Manfred Eigen. ${ }^{11}$ The model permits us to interpret such factors as threshold, initiation of the stimulus, latency, graded versus all-or-none response, and others, in terms of chemical events.

The model is an extension of the chemical theory. It comprises the assumption that basic excitation units are formed by a gateway surrounded by several basic protein assemblies, most probably an interlocked complex of the three proteins that process AcCh (FIgURE 3). ("Gateway" is an operational term used to describe dynamically coupled elements in the membrane at the region thought to be the permeation site for ion movements during excitation.) These basic excitation units are distributed over the whole excitable membrane, although the density may vary according to functional needs. If we assume that there are ten protein assemblies per unit and an even distribution, the distance in the electroplax membrane between the units would be $1,400 \AA$. The gateway probably contains fixed, mostly negative charges, and mono- and divalent ions. Structural changes in proteins and in macromolecular organizations such as membranes are strongly cooperative in nature. One consequence of this cooperativity is the possibility that far-reaching eonformational changes are caused by small changes of local environment. Ca ions are known to be

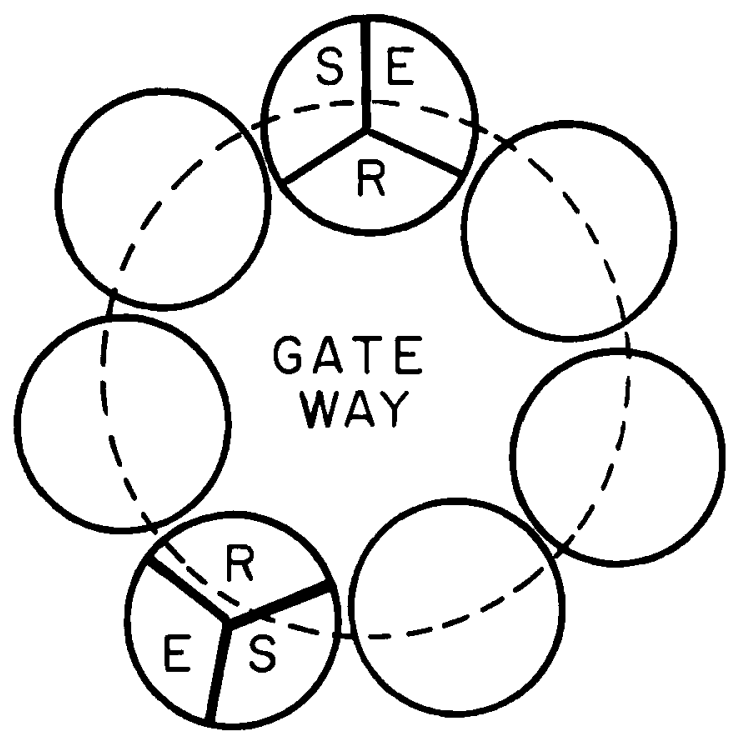

FIGURE 3. Scheme of the basic excitation unit (BEU). ( $S=$ storage protein; $R=$ receptor protein; $\mathbf{E}=$ acetylcholine esterase.) 
particularly potent in inducing conformational changes, as for instance in muscular contraction, and especially in surfaces rich in negatively charged groups. The low osmotic coefficient $(0.01)$, as determined by Katchalsky and colleagues, ${ }^{12}$ indicates that $99 \%$ of the $\mathrm{Ca}$ is bound. This strong binding is believed to be the reason for the prominent role of $\mathrm{Ca}$ in maintaining the structural and functional integrity of proteins and lipoproteins.

A crucial step in the development of the model was the observation by Neumann and Katchalsky ${ }^{13}$ that electric impulses of $20 \mathrm{kV} / \mathrm{cm}(20 \mathrm{mV}$ for a membrane of $100 \AA$ ) are capable of inducing conformational changes in biopolymers, with a displacement of the screening counterion atmosphere; the repulsion between charged components is increased thereby, and separation of ionic groups may occur. The initiation of an impulse may thus be due to the drop of the potential.

We assume in our model that the drop of potential leads to a conformational change of the storage protein, with a release of $\mathrm{AcCh}$ and its translocation to the receptor. This induces its conformational change, with a release of $\mathrm{Ca}$ ions, by allosteric action, for example (FIGURE 4). A weak impulse may lead to the release of only a few $\mathrm{AcCh}$ ions and may result in weak local responses such as the miniature potentials. When, however, the cooperative number of $\mathrm{AcCh}$ ions released reaches a critical value, the local response may after a certain latency period lead to the all-or-none response, the action potential. The sequence of chemical reactions that occurs during the action potential envisaged in the model is shown in FIGURE 5.

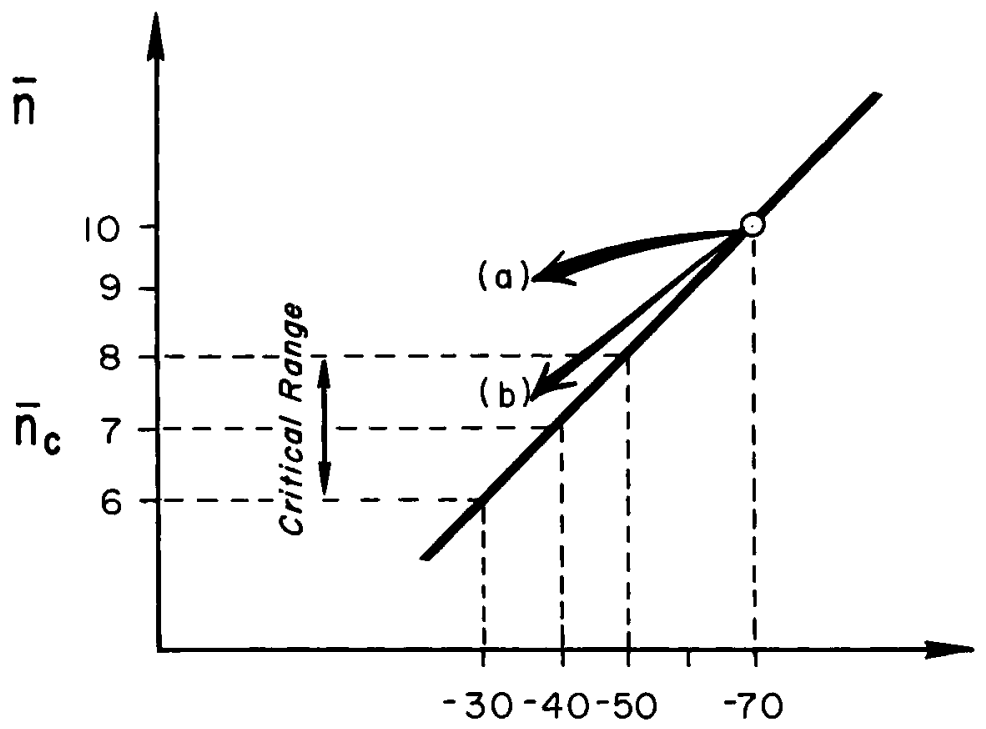

MEMBRANE POTENTIAL, $m V$

FIgURe 4. The function $n=f(\Delta \psi)$. For (a), a fast potential change, $n \gg n_{c}$. For (b), a slow potential change, $n \cong n_{c}$. 


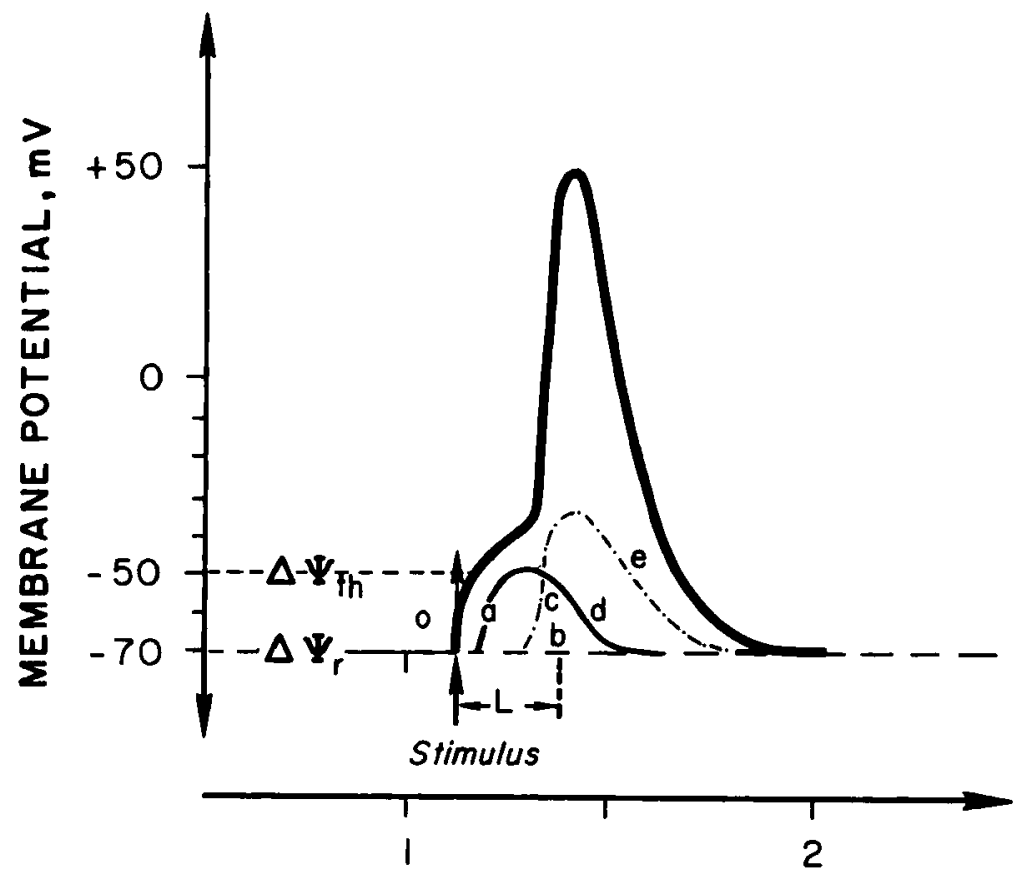

TIME, msec

FIGURE 5. Schematic representation of an action potential. At (o), the potential changes due to superposition of the above-threshold stimulus potential. At times (a) and (d) occur the AcCh release and hydrolysis, respectively; at times (b) and (c), the release of $\mathrm{Ca}^{2+}$ from the receptor and the opening of the gateway; and at (e), the reuptake of $\mathrm{Ca}^{2+}$ and the conformational relaxation that leads to the closure of the gateway. ( $L=$ latency; $\Delta \psi_{\mathrm{r}}=$ resting potential; $\Delta \psi_{11}=$ threshold potential.)

The elementary processes that change ion permeability are essentially the same in the axonal, in the nerve terminal, and in the postsynaptic membrane (FIgURE 6). For every 1,000 molecules released in the membrane at a nerve terminal, 20 to 40 million $\mathrm{K}$ ions enter the synaptic cleft. Rough estimates indicate that in the eel electroplax, the $\mathbf{K}$ ion concentration increases about fivefold. Such an increase would lead to a change of potential $[\Delta(\Delta \psi)]$ of about $-40 \mathrm{mV}$ across the postsynaptic membrane; this is sufficient to induce conformational changes of the storage proteins. The many differences of electrical parameters and pharmacological effects must be attributed to the dramatic changes of shape, structure, organization, and environment of junctional membranes (FIGURE 7). These organizational variations modify orientation of currents, distances, and so on; additional chemical factors (neuroeffectors such as catecholamines, for example) may act as modulators of the response. The so-called peculiarities of synaptic junctions, on which the transmitter theory was built, have been fully explained by a variety of experimental data. For example, the limitation of the action of $\mathrm{AcCh}$ when applied externally to the 
junctional parts of the membrane has been shown to be due to the presence of the insulating structural barriers that protect all conducting parts. Nobody has ever shown AcCh to be present in the extracellular fluid under physiological conditions. Loewi's experiments cannot be reproduced. Dale and his associates stressed that they never found a trace of $\mathrm{AcCh}$ in the perfusion fluid, except in the presence of eserine, that is, after having blocked the physiological

\section{JUNCTION}
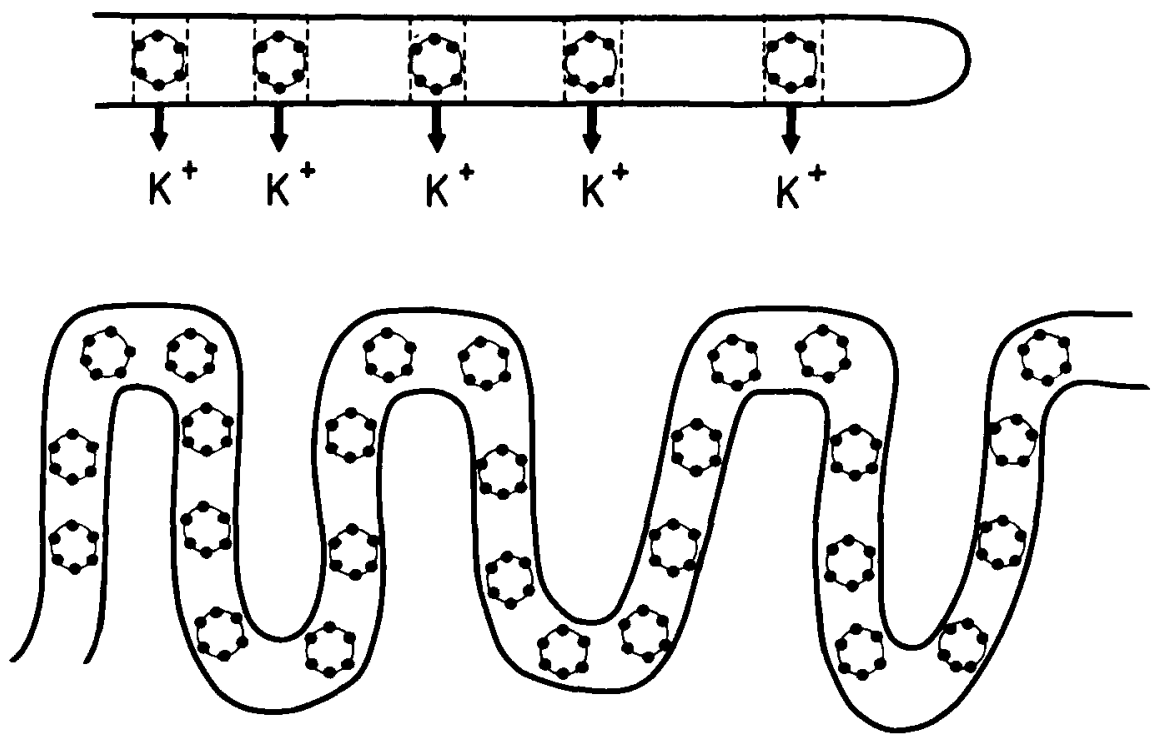

FIgURE 6. Localization and function of BEU at junction. The basic excitation units that effect the molecular processes responsible for the increased permeability of excitable membranes during electrical activity are present and functional in the membrane of the nerve terminal and in the postsynaptic membrane. The impulse that arrives at the terminal activates the signal, and the series of reactions amplify the signal in the same way as described for the axonal membrane. For every 1,000 molecules of AcCh that are activated in a nerve ending (this is about the actual order of magnitude of the molecules of $\mathrm{AcCh}$ activated) about 20-30 million $\mathrm{Na}^{+}$ions enter and the equivalent number of $\mathrm{K}^{+}$ions flow in the synaptic cleft. The $\mathrm{K}^{+}$ion concentration increases several-fold and produces a change of potential strong enough to induce a conformational change of $S$ in the postsynaptic membrane and to activate $\mathrm{AcCh}$, thus initiating the series of reactions that leads to the excitation of the effector cell.

removal mechanism. Today a vast amount of solid evidence exists which documents the unified concept of the role of $\mathrm{AcCh}$ as the signal that initiates the reactions that change ion permeability in all excitable membranes. The similarity of the basic molecular mechanism of this cellular function is in line with that established for other cellular functions such as power supply, muscle contraction, vision, and so on. 

5 Coser.

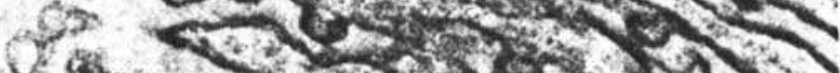

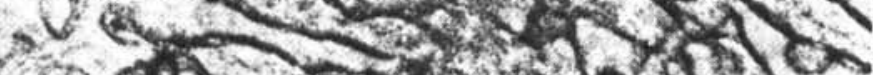

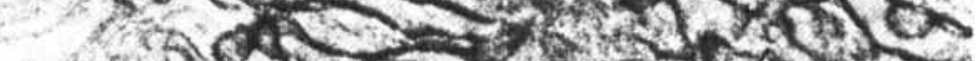

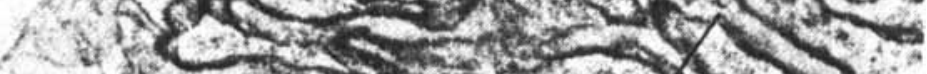

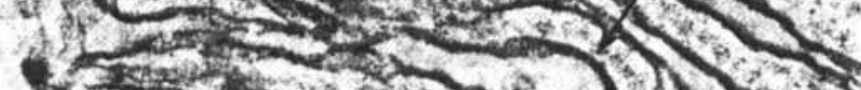

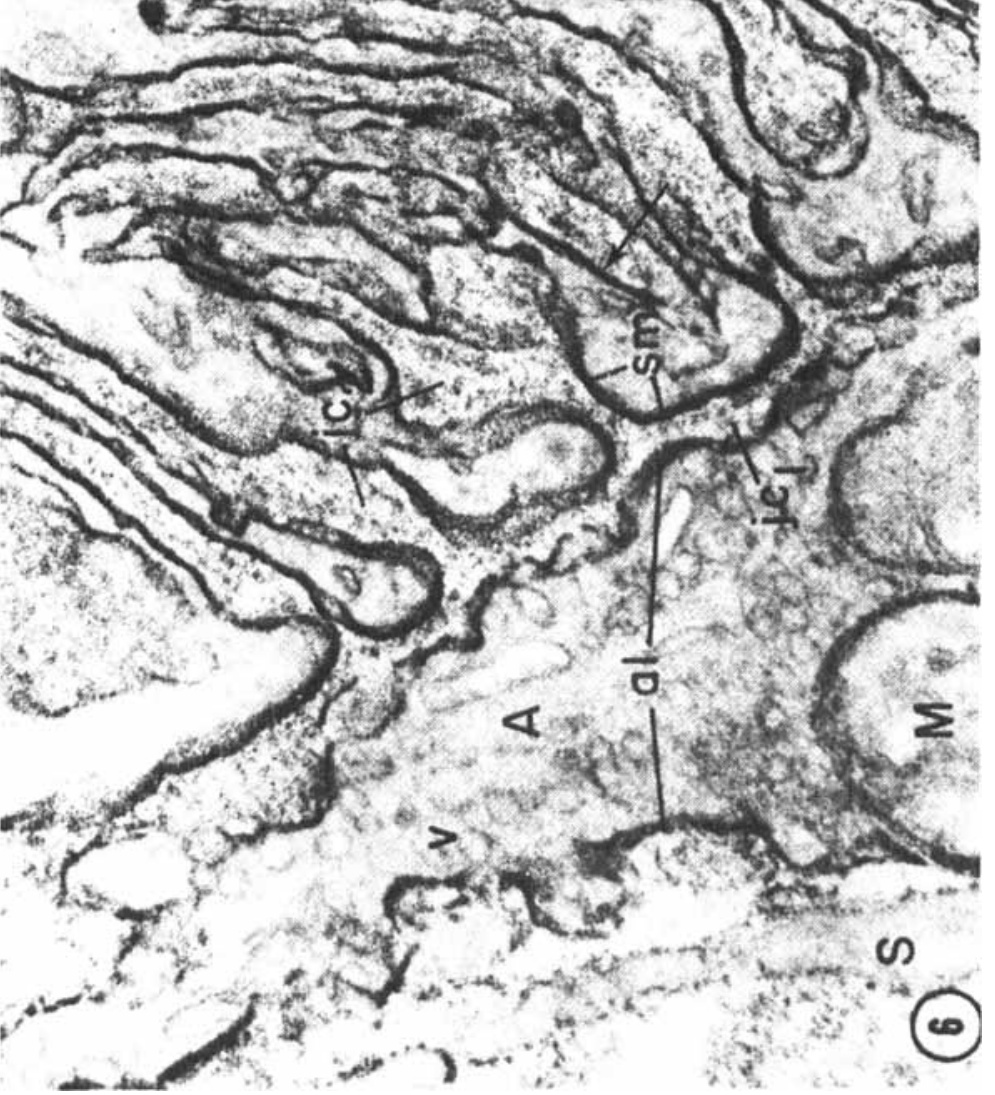
$\triangle$ 인

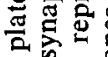

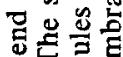
․ 댄

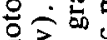
.

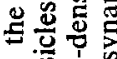
额 综

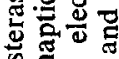

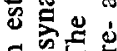
ठี 女 政 o 跣 武 ส

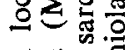

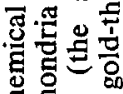
듕 . 的 ㄴ. so 당. 응

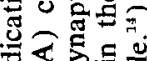

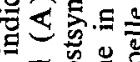
도음 可 응 政 年 응 部震 늘

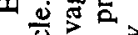

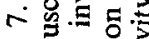
焉 5⿹丁口

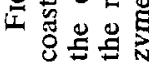




\section{REFERENCES}

1. Hilı, A. V. 1960. In Molecular Biology. Elementary Processes of Nerve Conduction and Muscle Contraction. D. Nachmansohn, Ed. : 17. Academic Press Inc. New York, N.Y.

2. CoLe, K. S. 1965. Physiol. Rev. 45: 340.

3. Nachmansohn, D, 1959. Chemical and Molecular Basis of Nerve Activity. Academic Press Inc. New York, N.Y.

4. Nachmansohn, D. 1970. Science 168: 1059.

5. Nachmansohn, D. 1971. Proc. Nat. Acad. Sci. U.S. 68: 3170.

6. Nachmansohn, D. 1971. In Handbook of Sensory Physiology. Vol. I. W. R. Loewenstein, Ed. : 18. Springer-Verlag Inc. Heidelberg, West Germany \& New York, N.Y.

7. Nachmansohn, D. 1973. In The Structure and Function of Muscle. Vol. III. G. H. Bourne, Ed. : 3. Academic Press Inc. New York, N.Y.

8. Changeux, J.-P., J. Gautron, M. Israel \& T. R. Podleski. 1969. C.R.H. Acad. Sci. (Ser. D) 269: 1788.

9. Kasai, M. \& J.-P. Changeux. 1971. J. Membrane Biol. 6: 24.

10. Katchalsky, A. 1967. In The Neurosciences. G. C. Quarton, T. Melnechuk \& F. O. Schmitt, Ed. : 326. The Rockefeller University Press. New York, N.Y.

11. Neumann, E., D. Nachmansohn \& A. Katchalsky. 1973. Proc. Nat. Acad. Sci. U.S. 70: 727.

12. Katchalsky, A. 1964. In Connective Tissue: Intercellular Macromolecules. Little, Brown and Co. Boston, Mass. Also in Biophys. J. S4: 9.

13. Neumann, E. \& A. Katchalsky. 1972. Proc. Nat. Acad. Sci. U.S. 69: 993.

14. Koelle, G. B. 1971. Ann. N.Y. Acad. Sci. 183: 5.

15. Hodgkin, A. L. \& A. F. Huxley, 1952. J. Physiol. 117: 500.

16. Dodge, F. A. \& B. Frankenhaeuser. 1959. J. Physiol. 148: 188. 